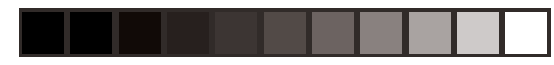

\title{
CONTINGÊNCIA E ANÁLISE INFINITA EM LEIBNIZ*
}

Ulysses Pinheiro **

\begin{abstract}
"Há certamente dois labirintos do espírito humano: um concerne à composição do contínuo, o outro à natureza da liberdade; todos os dois nascem de uma fonte idêntica no infinito". Leibniz, "Sobre a liberdade"1.
\end{abstract}

RESUMO Leibniz afirma em diversas ocasiões que a análise infinita é o conceito central para explicar a compatibilização entre determinismo e contingência. Não é evidente, no entanto, por que a aplicação analógica de um conceito matemático, tal como o de cálculo infinitesimal, poderia solucionar esse problema ontológico, nem em que sentido deve-se entender tal analogia. O objetivo deste artigo é esclarecer esses dois pontos.

ABSTRACT Leibniz says in various occasions that infinite analysis is the key concept to explain the compatibillity of determinism and contingence. It is not evident, however, why the analogical use of a mathematical concept, such as infinitesimal calculus, could solve this ontological problem, nor in

* Apresentei versões deste texto no II Colóquio de Filosofia Moderna da UFRGS, em um Colóquio sobre liberdade e necessidade na UFMG (ambos no fim de 2000) e no Seminário Filosofia da Linguagem (UFRJ/ Pronex Lógica, Ontologia e Ética), no começo deste ano. Agradeço a todos os que expuseram nessas ocasiões suas observações e críticas, graças às quais pude melhorar muito o original. Agradeço especialmente a Edgar Marques e Marcos André Gleizer, por sua leitura atenta e comentários valiosos.

** UFRJ/CNPq

1 Fragmento provavelmente escrito em 1689. Vorausedition zur Reihe VI in der Ausgabe der Akademie der Wissenschaften der DDR, Munique, 1980-1992, 10 fascículos (prépublicação dos textos de A VI iv), pp. 1767-1772. Esse texto apareceu em Nouvelles lettres et opuscules inédits de Leibniz, ed. por Foucher de Careil. Paris, 1857, pp. 178-185 e em Recherches générales sur l'analyse des notions et des vérités. Paris, P.U.F., 1998, pp. 329-335.

KRITERION, Belo Horizonte, $n^{\circ}$ 104, Dez/2001, p.72-96 
what sense one should understand such analogy. The aim of this paper is to elucidate these two points.

Palavras-chave Leibniz; contingência; infinito; necessidade; mundos possíveis

Deus é, segundo Leibniz, o objeto tematizado pelo conceito fundamental da metafísica, graças ao qual podemos reconhecer a diferença entre verdades necessárias e verdades contingentes. Só podemos compreender a estrutura da realidade pela tematização adequada desse conceito. Adotando o preceito metodológico segundo o qual todo raciocínio rigoroso sobre uma coisa qualquer deve estabelecer de antemão a possibilidade do objeto pensado pela idéia dessa coisa através da demonstração de que seus predicados essenciais são compossíveis, Leibniz trata, inicialmente, de mostrar que o objeto apresentado pela idéia de Deus pode ser real, ou seja, que pode existir um ser que é o agregado de todas as perfeições passíveis de um último grau, como a sabedoria e o poder. No entanto, a atribuição de onisciência e onipotência perfeitas a Deus, resultado da explicitação de seu conceito, parece antes contradizer do que fundamentar a distinção entre contingência e necessidade. Porque Deus conhece a priori todos os eventos de todos os mundos possíveis e predetermina toda a seqüência dos fatos que compõem o mundo atual, não é possível, aparentemente, haver aí nada de contingente.

É verdade que essa concepção da relação entre Deus e o mundo não é incompatível com uma certa distinção entre necessidade e possibilidade - e, daí, entre verdades necessárias e verdades contingentes, sendo as primeiras entendidas como aquilo que é verdadeiro em todos os mundos possíveis e as segundas como aquilo que é verdadeiro em pelo menos um, mas não em todos os mundos possíveis ${ }^{2}$. Entretanto, essa mesma concepção da relação entre Deus e o mundo parece, em um outro sentido, ser incompatível com a distinção entre necessidade e possibilidade. De fato, dado que Deus escolhe que este mundo atual, e não outro, exista porque ele é o melhor dos mundos possíveis, parece ser necessário que este mundo exista, bem como que seja necessário tudo o que ocorre nele ${ }^{3}$. Além disso, dado o Princípio da Identida-

2 Como se sabe, a aplicação irrestrita do Princípio de Identidade dos Indiscerníveis faz com que a teoria leibniziana dos juízos contrafactuais enfrente dificuldades consideráveis de formulação, mas não entrarei nesses detalhes aqui.

3 Para estabelecer claramente o comprometimento dessa concepção de Deus com o "necessitarismo", seria preciso tematizar a relação entre as perfeições da onisciência e da onipotência, pois saber que, digamos, $\mathrm{M}_{1}$ é o melhor dos mundos possíveis não obriga Deus a escolher criar $\mathrm{M}_{1}$. Por ora basta, contu- 

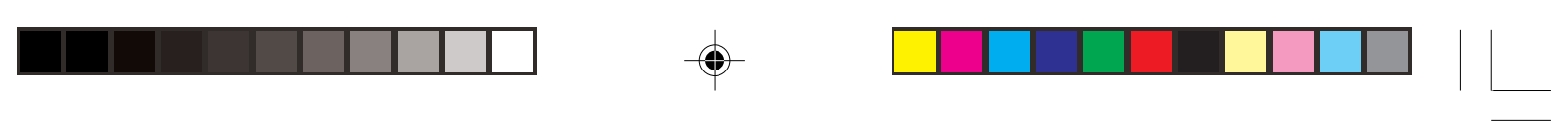

de dos Indiscerníveis, um mesmo objeto não pode existir em dois mundos possíveis diferentes, mas apenas em um; logo, parece que devemos concluir novamente que tudo o que ocorre a um dado objeto é necessário. O projeto de estabelecer o significado dos vários sentidos do ser a partir dos conceitos modais de necessidade, possibilidade e contingência teria, então, fracassado, pois os fundamentos da metafísica conduziriam a uma compreensão unívoca do ser.

Do ser para o conhecer, a conseqüência parece igualmente desastrosa; para entender isso, basta lembrarmos de algumas teses de Leibniz sobre a verdade. Toda predicação verdadeira tem seu fundamento na natureza das coisas (uma vez que a verdade é definida como a correspondência entre o pensamento e a realidade); daí se segue que o conceito do predicado deve estar contido no conceito do sujeito, uma vez que todas as propriedades atribuíveis a uma substância são determinações intrínsecas dessa substância, ou seja, são explicadas e têm seu fundamento em alguma característica da natureza da substância, sem o que não haveria uma conexão racional exibida pela predicação. Isso significa que a individuação de substâncias deve poder ser expressa em proposições verdadeiras por meios puramente qualitativos, i.e., por meio de noções completas correspondentes a cada indivíduo, de modo que todos os seus atributos façam parte de seu conceito ${ }^{4}$, entendido como a caracterização de uma "espécie ínfima”. Ora, tudo o que pertence ao conceito de uma espécie pertence necessariamente ao seu conceito. Logo, por princípio, não há nada que nos impeça de conhecer a priori tudo aquilo que pode ser dito verdadeiramente de uma substância ("por princípio" no sentido em que Deus sabe a priori tudo o que pode ser conhecido; é claro que nós, mentes criadas, devemos nos contentar com a experiência como fonte de grande parte de nossos conhecimentos - mas isso deriva da limitação de nossas faculdades, e não da natureza da própria coisa, na medida em que ela é objeto de uma inteligência ilimitada). Isso parece significar que toda predicação verdadeira ou falsa é necessariamente verdadeira ou falsa ${ }^{5}$, ainda que, do

do, notar que do necessário parece só poder se seguir o necessário, e que Deus tem necessariamente a perfeição da bondade.

4 Ou pelo menos sejam derivados de seu conceito. Não abordarei aqui a distinção entre predicados essenciais e predicados relacionais. É claro que, no intelecto de Deus, a noção de cada indivíduo é apreendida por um ato simples de intuição.

5 Cf. o ensaio "Sobre a liberdade" (supra, nota (1)), especialmente pp. 330-331: "Or je m'aperçus que les propositions vraies affirmatives, universelles ou singulières, nécessaires ou contingentes, ont toutes ceci en commun que leur prédicat est dans leur sujet, c'est-à-dire que la notion du prédicat est enveloppée dans celle du sujet sous un certain rapport; et qu'en cela consiste le principe de l'infaillibilité, quel que soit le genre de la vérité, chez Celui qui connaît tout a priori. Mais cette découverte sembla augmenter la difficulté. Si, en effet, la notion du prédicat était dans celle du sujet pour un temps donné, comment, sans contradicition et impossibilité, le prédicat pouvait-il maintenant être absent du sujet sans que la notion de celui-ci n'en souffre?". Deve-se notar que, apesar de Leibniz afirmar que as proposições contingentes 
ponto de vista das mentes criadas guiadas pela experiência sensível, haja a ilusão da contingência.

A solução mais elaborada de Leibniz para evitar as tendências "necessitaristas" presentes potencialmente em sua metafísica e em sua teoria da verdade consiste em um apelo à análise infinita; é isso, ele nos conta, que o afastou da beira do "abismo espinosista", no qual esteve prestes a cair ${ }^{6}$. A compreensão de que a estrutura ontológica do real comporta em si o infinito, correlacionado ao entendimento e à vontade infinitos de Deus, é o caminho que o conduziu para longe desse abismo. Nesse caso, do ser para o conhecer, a conseqüência é boa: uma explicação compatibilista da conjunção entre determinismo e contingência consiste na compreensão do modo como o real infinito se exprime no pensamento, ou seja, na distinção entre provas finitas e infinitas. Trata-se, em suma, de esclarecer quais são as condições de verdade de proposições que envolvem o infinito ${ }^{7}$.

Uma teoria filosófica do infinito já se encontra em Espinosa, sem que esse a tenha explorado como alternativa ao fatalismo, mas Leibniz via aí a chave para distinguir predicados essenciais de predicados acidentais sem recair no erro oposto, o de Aristóteles, na medida em que esse último propunha que a matéria é um elemento explicativo da individuação, origem da contingência e resquício ininteligível do real. A fonte da contingência, diz Leibniz, não é um princípio qualquer que obscureça a inteligibilidade perfeita do real: ela é a vontade divina, que obedece a uma Lei da Vontade e ao Princípio de Razão Suficiente, e cuja condição de aplicação é dada pelo fato de que a noção completa das substâncias individuais é composta pela representação de infinitas propriedades (e também, é claro, pelo fato de que os infinitos mundos possíveis são compostos por infinitos objetos). A inteligibilidade do real implica o determinismo e não exclui a contingência. Ou melhor: há contingência porque há determinismo.

No entanto, muitos duvidam, desde a época de Leibniz até hoje, que ele nos tenha oferecido mais do que uma metáfora irrecuperável com seu uso do cálculo infinitesimal em matemática como modelo para resolver o problema ontológico da contingência. Desde comentadores mais simpáticos, como Adams $^{8}$ (que acredita que Leibniz nos oferece critérios claros de distinção entre verdades contingentes e verdades necessárias baseado na estrutura -

também apresentem uma conexão interna entre sujeito e predicado, ele mesmo reconhece a dificuldade dessa extensão da noção intensional de verdade para além do domínio das proposições necessárias.

6 Idem, ibidem, (F. de C., p. 179).

7 Deve-se notar que se trata de condições de verdade, e não de uma explicação da contingência pela limitação de nosso conhecimento.

8 Cf. Leibniz. Determinist, Theist, Idealist. New York, Oxford, , Oxford University Press, 1994, Cap. 1. 
infinita ou finita, respectivamente - da prova das proposições que as expressam, mas que afirma, por outro lado, que nós, leitores críticos da obra leibniziana, não podemos aceitar essa distinção e a conseqüente tese de que há verdades analíticas contingentes) até outros francamente adversos a essa solução, como Blumenfeld ${ }^{9}$ (que relega a metáfora à categoria de um instrumento inutilizável quando aplicado à semântica e à ontologia), passando por um amplo espectro de posições (como a de Ishiguro ${ }^{10}$, que também rejeita, no final de seu livro, a eficácia do recurso ao infinito), parece haver consenso de que a análise infinitesimal está muito bem no lugar de onde ela nunca deveria ter saído, a saber, no cálculo matemático. Sua aplicação à metafísica seria, segundo os mais críticos, uma resposta obscura para um problema insolúvel.

De fato, tal como proposto em sua formulação mais genérica, o programa "compatibilista" entre determinismo e contingência é insolúvel simplesmente porque ele apresenta uma contradição manifesta: se todos os eventos do mundo são determinados, isso é incompatível com a existência de fatos contingentes, entendidos como fatos absolutamente indeterminados. O compatibilista pode mostrar que o determinismo não exclui (e talvez mesmo implique) a contingência, mas a união daí resultante não é mais a dos elementos originais. Compatibilizar significa, em grande medida, esclarecer e modificar os conceitos de determinismo e contingência utilizados pelo senso comum.

Partirei do pressuposto de que é possível justificar a seguinte tese: Leibniz não é um "superessencialista" ("superessencialista” é o termo utilizado por Mondadori ${ }^{11}$ para sustentar a tese de que não há contingência de predicação, mas apenas de existência, de tal modo que a diferença entre predicados essenciais e acidentais seria reduzida à diferença entre predicados permanentes e temporários ${ }^{12}$ ). Ou seja, a contingência a ser resgatada não diz respeito

9 Cf. "Leibniz on Contingency and Infinite Analysis". In: Philosophy and Phenomenological Research, Vol. XIV, n. 4, Junho de 1985.

10 Cf. Leibniz's Philosophy of Logic and Language. London: Duckworth, 1972.

11 Cf. "Leibniz on the Doctrine of Inter-World Identity". In: Studia Leibnitiana 7 (1975), p. 22-57.

12 Cf. G. Grua (ed.), 311, Leibniz: Textes Inédits, Paris, 1948: "Nessa noção completa do Pedro possível, a qual admito que Deus observa, está contido não somente o que é essencial, ou seja, necessário, a saber o que se segue de noções incompletas ou específicas e é, por conseguinte, demonstrado ex terminis de tal modo que o contrário implica uma contradição, mas também o que é contingente ou, por assim dizer, existencial". Esse texto nos mostra claramente que Leibniz pretende manter uma distinção, no interior do mundo criado, entre predicação necessária (que tem lugar entre predicados que representam espécies e gêneros, tais como "ser homem" e "ser racional", bem como entre os indivíduos e essas espécies e gêneros que os caracterizam como indivíduos de um certo tipo) e predicação contingente (que diz respeito aos atributos particulares de indivíduos particulares). Essa distinção não eqüivale à distinção entre predicados permanentes e predicados transitórios, ou melhor, a primeira distinção não pode ser reduzida à outra, mas é porque algo é necessário que ele é permanente, e porque algo é contingente que ele é transitório. Se não fosse assim, a contingência e a necessidade não seriam baseadas em razões, mas no 
apenas à possibilidade de um objeto existir ou não na realidade (como afirma Russell ${ }^{13}$ ), mas à própria conexão entre os conceitos do sujeito e do predicado em uma proposição verdadeira afirmativa. Há uma distinção de natureza (que não exprime apenas uma variação temporal) entre predicados essenciais e predicados acidentais e a análise infinita é o modelo adequado para explicar tal distinção.

Meu argumento tem duas partes. I- Em uma primeira etapa, trata-se de mostrar que a conexão entre os predicados acidentais e o sujeito de uma proposição contingente é tal que, devido ao fato de o sujeito designar uma substância composta de infinitas propriedades, é impossível estabelecer uma conexão necessária entre o conceito do sujeito e o conceito do predicado. II- Em uma segunda etapa, trata-se de mostrar que $a$ infinitude das propriedades de uma substância singular é capaz de fornecer a base para uma explicação de por que a conexão entre sujeito e predicado é, nesses casos, contingentemente verdadeira ou falsa. Como fica patente, a primeira parte do argumento estabelece uma conclusão puramente negativa, enquanto que a segunda termina com uma conclusão positiva, capaz de gerar uma explicação para o fenômeno investigado. Examinemos, pois, as duas partes separadamente.

\section{I- Há proposições que enunciam conexões necessárias, como:}

\section{“O homem é um animal”.}

Para mostrar que o conceito de animal está contido no conceito de homem, devemos antes de tudo analisar esse último:

mero fato observado da distribuição aleatória de propriedades temporárias e permanentes; ora, isso vai contra o Princípio de Razão Suficiente.

13 Cf. A Critical Exposition of the Philosophy of Leibniz, with an Appendix of Leading Passages. London: Allen \& Unwin, 1937 ( $2^{\text {a }}$ ed.). 
O lado direito da análise em árvore, relativo ao significado de "racional”, pode permanecer vago. O que é importante notar é que as propriedades $\mathrm{P}_{1}, \mathrm{P}_{2}, \mathrm{P}_{3}$ e $\mathrm{P}_{4}$ são tomadas aqui, por suposição, como sendo as notas características que definem o que é "ser um animal” (é claro que, de fato, há condições mais complicadas do que apenas essas para definir tal propriedade, mas $\mathrm{o}$ argumento pode ignorar esse fato).

O que devemos observar é que a proposição “O homem é um animal” foi reconduzida, em um número finito de passos, a uma identidade ("O animal racional é um animal”) porque, de um conjunto completo de propriedades $\left[\mathrm{P}_{1}, \mathrm{P}_{2}, \mathrm{P}_{3}\right.$ e $\left.\mathrm{P}_{4}\right]$, foi provado que se segue necessariamente a propriedade relevante ("ser um animal"). Ou seja, o conjunto $\left[\mathrm{P}_{1}, \mathrm{P}_{2}, \mathrm{P}_{3}\right.$ e $\left.\mathrm{P}_{4}\right]$ é equivalente a "ser um animal”; o significado dessa equivalência pode ser expresso assim: "Se algo tem as propriedades essenciais de $x$, então esse algo é $x$ ".

Logo, demonstrar que o conceito de animal está contido no conceito de homem significa que, ao identificarmos distintamente um objeto ("homem”), é possível provar que ele cai ou não sob o escopo de um certo predicado ("ser um animal”). Ou ainda, se pensarmos no conceito do sujeito e no conceito do predicado sendo usados em proposições (do tipo " $x$ é um homem” e " $x$ é um animal”), podemos dizer que uma proposição implica a outra se a primeira designa um subconjunto da última. (Deve-se notar que $\mathrm{P}_{1}, \mathrm{P}_{2}, \mathrm{P}_{3}$ e $\mathrm{P}_{4}$ são suficientes para definir e apresentar clara e distintamente um objeto - nesse caso, um objeto geral, uma espécie abstrata).

Há outras proposições que enunciam conexões contingentes, como:

“Judas é o traidor do Cristo”. 
Essa frase exprime uma propriedade contingente de Judas e, mais do que isso, uma ação realizada livremente por ele; como por ora só nos interessa o problema da contingência, sobre o qual o problema da liberdade será "superveniente", deixaremos de lado esse segundo aspecto da propriedade de "ser traidor" (o que não significa, porém, que não seja relevante em alguns casos parafrasear "Judas é o traidor do Cristo" por "Judas escolheu livremente trair o Cristo"14). Há certas propriedades que são essenciais a Judas; a conexão dessas propriedades essenciais com o conceito singular de Judas é, portanto, necessária. Esse é o caso de predicados sortais como "ser um homem”, que representam classes empiricamente dadas (e daí se segue, evidentemente, que é possível provar, por um silogismo simples, que, se Judas é um homem, Judas é um animal — ou seja, os predicados sortais estão conectados necessariamente com os gêneros dos quais são espécies). Podemos retirar daí uma tese importante para a explicação da contingência a partir da análise infinita, a saber: o uso de predicados sortais mais genéricos ${ }^{15}$ mostra que nem toda atribuição de propriedades a uma substância composta de infinitas propriedades gera uma verdade contingente acerca dessa substância. Há propriedades necessárias que são condição de possibilidade para identificarmos os objetos singulares - como Judas. Os conceitos sortais mais genéricos definem o tipo de objeto que Judas é, e sem eles o indivíduo não seria dado (nem como instância de uma espécie nem muito menos como objeto de uma análise infinita). Por contraste com essa função sortal, poderemos agora entender quais são as características dos predicados que exprimem propriedades contingentes atribuídas a uma substância composta de infinitas propriedades.

Voltemos à frase "Judas é o traidor do Cristo". Para mostrar que o conceito de traidor está contido no conceito de Judas, devemos antes de tudo analisar esse último:

14 O problema da liberdade acrescenta várias dificuldades ao problema da contingência, dos quais não trataremos aqui.

15 A qualificação "mais genéricos" visa mostrar que a distinção entre conceitos relativos a classes e conceitos referentes a indivíduos é, em certo sentido, uma distinção de graus, uma vez que, como vimos, segundo Leibniz, ambos são, de certa forma, sortais. Em outro sentido, porém, a distinção é qualitativa, e não meramente de graus: ainda que os indivíduos sejam "espécies ínfimas", as noções completas que Ihes correspondem têm por referência coisas singulares, enquanto que os conceitos expressos pelos predicados sortais mais genéricos não denotam objetos, mas são conceitos que representam propriedades gerais. Uma substância singular pode ser descrita precisamente como o agregado das infinitas qualidades que representam propriedades intrínsecas e, derivadamente, relações, agregado esse que deriva da noção individual e simples representada intuitivamente no intelecto de Deus. Há objetos abstratos (como o Círculo geométrico) que podem ser pensados como os correlatos da composição finita de algumas dessas propriedades, muito embora eles não existam fora do pensamento. 

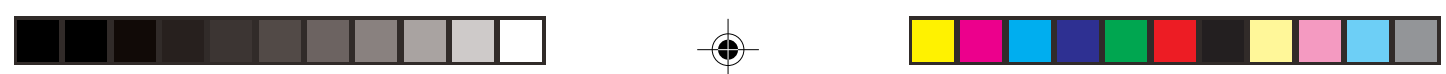

CONTINGÊNCIA E ANÁLISE INFINITA EM LEIBNIZ

Nesse caso, o lado direito da estrutura em árvore designa as propriedades essenciais de Judas, que se articulam segundo um nexo finito de razões, enquanto que o lado esquerdo representa suas propriedades contingentes ${ }^{16}$. Algumas dessas propriedades, como "ser o filho de Simão", são relacionais, mas não estou considerando neste momento a diferença entre propriedades intrínsecas e relacionais, pois não é a partir dela que se pode entender a diferença entre propriedades essenciais e contingentes (em outras palavras, tanto propriedades intrínsecas quanto propriedades relacionais podem ser contingentes). Sendo assim, examinemos o modo de encadeamento dessas propriedades contingentes.

Como vimos antes, no caso das proposições necessárias, é possível demonstrar, em um número finito de passos, que há identidade entre os termos que as compõem (como nas propriedades "ser um animal racional” e "ser um animal”) — ou seja, justamente porque suas propriedades são finitas, um objeto cai ou não cai, de modo determinado, sob certo conceito, e, que ele caia ou não sob esse conceito é provado usando-se apenas o Princípio de Identidade e o Princípio de Contradição. Por outro lado, em um objeto composto por infinitas propriedades, não é possível demonstrar que há uma identidade do lado esquerdo com o lado direito da equivalência proposta (já que uma demonstração requereria que a identidade fosse estabelecida em um número finito de passos ${ }^{17}$ ). Tomemos qualquer $x=y$ onde $x$ é uma cadeia infinita de elementos:

$$
1 / 2+1 / 4+1 / 8+\ldots=1
$$

16 É claro que essas últimas também poderiam ser representadas por uma estrutura em árvore, mas a seqüência linear facilita a visualização do argumento.

17 Distinguimos aqui entre os termos "prova" (que pode ser finita ou infinita) e "demonstração" (que só pode ser finita). Uma prova infinita é um algoritmo com passos infinitos. 
Por mais que haja uma aproximação infinita para o número 1, que exprime a tendência ou o limite da série, nunca encontraremos um objeto do lado esquerdo da identidade que contenha as propriedades do número 1. "Nós nunca encontraremos" - o pronome "nós" é usado aqui para incluir Deus: nem os homens nem Deus encontrarão o fim da série, pela simples razão de que a série não tem fim. Não há nada lá para ser descoberto, apenas um limite ${ }^{18}$.

Deus vê a priori todas as séries infinitas, por um ato único de intuição que percorre "toda" a série (lembremos que o intelecto de Deus I- também é infinito e II- não opera no tempo - logo, percorrer "toda" a série não deve ser entendido como I- chegar até o fim, pois não há fim, nem como II- um ato que continua a ser reiterado indefinidamente). Nós, homens, podemos provar a priori (por demonstrações temporalmente localizadas) proposições necessárias sobre o limite de certas séries matemáticas; não temos, porém, a mesma habilidade no que se refere às séries de objetos naturais ${ }^{19}$. Mas, tanto no caso dos objetos naturais quanto no dos objetos matemáticos, nada além de uma decisão nos permite (a nós homens e a Deus) formular uma identidade, ou seja, atribuir a uma série infinita o valor de seu limite.

Há uma tendência a incluir o conceito de "traidor do Cristo" do lado esquerdo da identidade, mas nunca será dado um objeto que contenha as características completas que permitam identificá-lo às (ou deduzir dele as) características que definem a traição do Cristo. Da série $\left[\mathrm{P}_{1}, \mathrm{P}_{2}, \mathrm{P}_{3}\right.$, P¥], não se segue logicamente a propriedade "ser o traidor do Cristo".

II- Passemos agora à segunda etapa de meu argumento, na qual se trata de mostrar que $a$ infinitude das propriedades de uma substância singular é capaz de fornecer a base para uma explicação de por que a conexão entre sujeito e predicado é, nesses casos, contingentemente verdadeira ou falsa. Para entender mais claramente a aplicação analógica do conceito de limite matemático à explicação semântica das proposições contingentes, distingamos três situações em que um objeto pode ser pensado:

1- Um objeto vago é pensado, seja ele singular ou universal, como sendo dotado de poucas propriedades, insuficientes para conceber distintamente se ele cai ou não sob um certo predicado; digamos que um objeto, cuja idéia é intrinsecamente obscura e confusa, tenha as propriedades $\left[\mathrm{P}_{1}, \mathrm{P}_{2}, \mathrm{P}_{3}, \ldots\right]$, onde as reticências indicam que a enumeração de propriedades continua, mas que

18 Cf. "Sobre a liberdade”, p. 333: "Dieu seul voit, non pas, bien entendu, la fin de la résolution, qui n'existe pas, mais tout au moins la liaison des termes, c'est-à-dire l'enveloppement du prédicat dans le sujet, car il voit quant à lui tout ce qui est dans la série".

19 O fato de os entes matemáticos serem objetos abstratos explica essa diferença: enquanto objetos abstratos, há neles características que podem ser provadas necessariamente, i.e., em um número finito de passos (por ex., certa relação proporcional entre os números). 

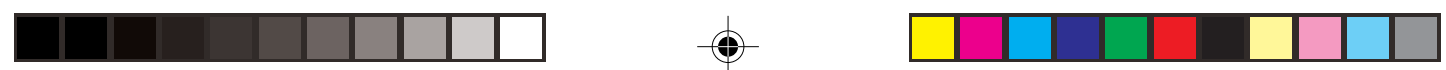

só conhecemos as três primeiras. Inúmeras propriedades poderiam completar a lista ou, dito de outra forma, a maior parte das propriedades existentes não seria excluída ${ }^{20}$. Ora, no caso dos objetos vagos, é um fato puramente extrínseco pensar que algo "retangular, com $30 \mathrm{~cm}$ de comprimento e pesando $1 \mathrm{k}$ " (supondo que essas propriedades correspondam respectivamente a $\mathrm{P}_{1}, \mathrm{P}_{2} \mathrm{e}$ $\mathrm{P}_{3}$ ) tenha a cor azul ou vermelha $\left(\mathrm{P}_{4}\right)$. A ausência de necessidade na conexão dos predicados é explicada pela vagueza de seu conteúdo.

2- Um objeto é clara e distintamente pensado como sendo composto de um número finito de propriedades. Ele pode ser:

2.1- um objeto abstrato (o Círculo Geométrico, o Homem, a Árvore);

2.2- um objeto singular - e, portanto, concreto -, composto de um número de propriedades variável, que pode chegar a ser enorme, mas que é, ainda assim, dada a restrição inicial, finito.

O caso descrito em 2.2 não tem, é claro, lugar na teoria leibniziana dos objetos, embora 2.1 seja um de seus elementos essenciais. Nos dois casos, porém, é possível provar que um objeto cai ou não cai necessariamente sob um certo predicado. Ou seja, dada a finitude do objeto, ele não tem acidentes. O que nos interessa particularmente aqui é 2.2; se um objeto desse tipo existisse, tudo seria determinado sem que fosse possível compatibilizar determinismo e contingência. Isso se torna mais claro ao pensarmos no modelo da causalidade: se Judas é uma substância finita composta de um número finito de propriedades (para simplificar, nos restrinjamos momentaneamente a propriedades psíquicas), então estão dadas todas as causas a favor (e excluídas todas as causas contrárias) que nos permitem concluir necessariamente que ele trairá o Cristo. Daí se segue que ele necessariamente trairá o Cristo. Ele duvida da verdade revelada, deseja dinheiro, sente-se mal ao pensar na possibilidade de trair seus Irmãos, etc., pensamentos esses que constituem sua mente de tal forma que o desejo de trair sobrepuja — momentaneamente, até o arrependimento e o suicídio - os escrúpulos em trair seu Mestre). Alguém que conhecesse todos os seus estados mentais poderia prever a necessidade de seu ato.

20 É verdade, porém, que talvez um número muito grande também fosse excluído - por ex., se $\mathrm{P}_{1}$ simbolizasse "ser retangular", todas as propriedades que não fossem compatíveis com as coisas retangulares seriam postas de lado imediatamente; poderíamos mesmo dizer que, sendo infinito o número de propriedades existentes, seriam excluídas infinitas propriedades - um infinito diferente, porém, do que aquele que seria admitido como atributo do objeto em questão -, o que faz parte dos aparentes paradoxos do conceito de infinito. $\mathrm{O}$ que seria excluído nesse caso seriam as propriedades contraditórias com $\mathrm{P}_{1}, \mathrm{P}_{2} \mathrm{e}$ $\mathrm{P}_{3}$, o que pode designar um número infinito de propriedades. Entretanto, dentre as propriedades que não contradizem o conjunto formado por $P_{1}, P_{2}$ e $P_{3}$, a continuação da série $\left(P_{4} \ldots . . P ¥\right)$, sendo também infinita, poderia incluir tanto uma certa propriedade $\mathrm{P}$ quanto sua negação não-P (ou melhor, uma propriedade qualquer P' que implicasse não-P). 
Ainda que esse modelo seja suficiente para uma interpretação epistemológica da contingência (por ex., algo como a análise condicional da liberdade proposta por Moore, segundo a qual Judas poderia ter agido diferentemente, se assim o tivesse querido ${ }^{21}$, ele não é suficiente para uma interpretação ontológica da contingência, no sentido em que essa última requer a ausência de necessidade e a possibilidade real - e não apenas condicional - de Judas ter agido diferentemente. Evidentemente, o modelo causal exposto acima para explicar as limitações da finitude pode ser substituído facilmente e sem prejuízos pelo modelo da compossibilidade e da harmonia universal de propriedades intrínsecas às substâncias. Essa mudança de vocabulário corresponderia, nos termos da filosofia leibniziana, à passagem de uma explicação fenomênica para uma explicação metafísica da realidade ${ }^{22}$.

3- Um objeto é distintamente pensado como sendo composto de infinitas propriedades; logo, segundo Leibniz, ele é uma substância singular. De fato, é importante observar que um objeto abstrato, como o Círculo geométrico, deve ser pensado clara e distintamente com um número finito de propriedades (pelo menos se tomarmos o conceito de propriedade como exprimindo qualidades logicamente independentes umas das outras; caso contrário, infinitas propriedades analíticas - e, nesse caso, o critério de analiticidade deve ser o de sinonímia - poderiam ser retiradas do conceito do Círculo). Isso não significa que nós, mentes criadas, tenhamos acesso a todas as indefinidas propriedades logicamente independentes que compõem o Círculo geométri$\mathrm{CO}^{23}$ — e muito menos às infinitas propriedades que compõem as substâncias singulares.

21 Segundo Moore (in: "Free Will”. In: Ethics. London, 1912), ainda que o querer seja ele mesmo determinado, como Judas não conhece toda a seqüência causal que o determina nem pode prever a continuação dos eventos na direção do futuro, isso garante que é possível atribuir-lhe responsabilidade moral e uma auto-representação de si mesmo enquanto agente como se fosse livre.

22 Nesse caso, porém, como Leibniz admite que há relações causais entre a substância e suas determinações internas, negando apenas a causalidade entre substâncias, a mudança de vocabulário não indica dois níveis distintos de explicação.

23 O adjetivo "geométrico" serve nesse caso não só para designar um domínio da realidade (que é mais amplo do que o domínio da existência) ao qual esse objeto pertence, mas também para indicar um modo de considerar esse objeto (o Círculo "visto geometricamente"). Esse "modo de considerar" é importante para estabelecer distinções entre vários graus de abstração relativamente aos conceitos gerais - desde os conceitos com aplicação empírica, como o de Homem ou o de Árvore, até os que só têm validade em um domínio da realidade diferente do dos fenômenos espaço-temporais particulares, como o de Círculo ou o de Ponto geométricos. É preciso distinguir entre conceitos gerais empíricos (menos abstratos) e puros (mais abstratos). Os conceitos gerais empíricos, como o de Homem, o de Judas (considerado em geral, como uma classe de objetos que são elementos de vários mundos possíveis) e o de Círculo (mas não o do Círculo "visto geometricamente") podem ser instanciados nos diversos mundos possíveis. Os conceitos gerais puros - como o de Círculo e o de Ponto geométricos - nunca podem ser instanciados no mundo, como um item submetido ao espaço e ao tempo. O conceito de instanciação, aplicado apenas aos conceitos empíricos, mostra em que sentido o infinito está compreendido nesses últimos: há infinitas maneiras de se instanciar os conceitos de Homem ou de Árvore. Já no caso dos conceitos puros, não há essa relação de instanciação, eles se referem a objetos abstratos, e tudo neles está conectado segundo 

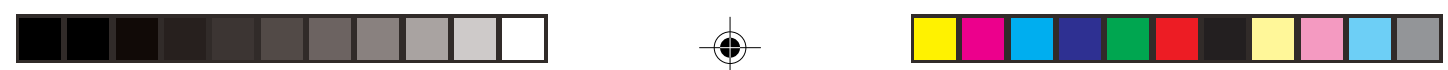

Nesse último caso, a conexão entre, por ex., "O livro que comprei ontem” " "ser azul” é um fato — um fato lógico, poderíamos dizer, dada a teoria leibniziana da verdade, fato esse proveniente da combinatória dos infinitos compossíveis. Para evitar confusões com o sentido previamente mencionado de analiticidade ou necessidade lógica, poderíamos modificar os termos e dizer que, nas proposições contingentes, nos deparamos com um fato racional ou um fato da razão. Esse fato é "visto" por Deus (i.e., está previsto como devendo acontecer na ordem do mundo) e é, por isso mesmo, predeterminado, dado o decreto atual que cria este mundo e os decretos possíveis que unem o predicado "ser azul" a "O livro que comprei ontem". Deus não se limita, portanto, a contemplar esse fato, mas, antes, o produz virtualmente em seu intelecto através da compreensão do mundo possível que o contém e no qual estão contidos os Seus decretos possíveis. O que é produzido dessa maneira não é apenas a existência do livro azul (como afirmam Russell e Mondadori), mas a própria conexão entre o livro que comprei ontem e a cor azul, mesmo que ela ocorra em um mundo possível não existente; o caráter factual dessa conjunção é derivado da vontade divina, que, sendo guiada pelo Princípio de Razão Suficiente e pelo Princípio de Perfeição, é, portanto, (como ensina $\operatorname{Rescher}^{24}$ ) o fundamento da contingência. A conjunção do predicado e do sujeito repousa sobre a vontade de Deus, mediada (ou concretizada) pelas leis maximamente universais e pelas leis subalternas da natureza e pela consideração simultânea de todos os infinitos objetos dos infinitos mundos possíveis, tendo em vista a produção do melhor. Em suma, a contingência que é assim explicada não se refere apenas à existência, mas à própria predicação ${ }^{25}$.

Isso significa, como disse acima, que Deus produz conceitos, e não apenas os encontra como que "prontos" em seu intelecto. Qual é o significado preciso da aplicação do conceito de "criação" não ao mundo atual, mas a conceitos e mundos possíveis? Há um sentido muito preciso em que se pode

relações finitas - logo, todas as verdades formuladas sobre eles são necessárias. (É claro que tudo o que pertence ao conceito de Homem pertence necessariamente ao conceito de Homem, mas nem todas as proposições em que aparece esse conceito enunciam verdades necessárias). Uma distinção ulterior deve ser feita entre dois tipos de conceitos gerais empíricos, a saber: entre os que designam espécies universais (como o conceito de Homem) e os que se relacionam às espécies ínfimas (como o conceito de Judas). O conceito geral de Judas, usado para a formulação de juízos contrafactuais, só pode ter no máximo uma instância em cada mundo possível (embora, como todos os conceitos empíricos, não seja instanciado em outros infinitos mundos possíveis). Por essa razão, quando aparece em juízos contrafactuais, o nome que o simboliza tem por referência o conceito geral individual de Judas, ao passo que o seu sentido é a situação possível em que é instanciado.

24 Cf. "Contingence in the Philosophy of Leibniz". In: The Philosophical Review, vol. 61, no. 357 (1952), pp. 26-39.

25 Cf. Ezio Vailati, "Leibniz on Necessary and Contingent Predication" - in: Gottfried Wilhelm Leibniz Critical Assessments. Londres e Nova York: Routledge, 1994, pp.330-349. 
e deve entender essa tese, a saber: os mundos possíveis são incompreensíveis sem que neles estejam figurados os decretos possíveis de Deus, os quais são o fundamento da inclusão do conceito do predicado no conceito do sujeito. Essa tese não deve ser entendida, porém, como uma versão da teoria cartesiana da "livre criação das verdades eternas por Deus", pois para Leibniz há proposições que são verdadeiras em todos os mundos possíveis, i.e., são necessárias, as quais, portanto, Deus não produz em nenhum sentido, mas antes encontra em seu intelecto e limita-se a contemplá-las. Há outras proposições, porém, que são contingentes, i.e., cuja verdade ou falsidade depende não apenas do decreto atual de Deus (que cria este mundo atual), mas também de Seus decretos possíveis. Eis como o próprio Leibniz exprime essa distinção (a citação é longa, mas tem o mérito de apresentar de forma resumida o principal ponto da discussão sobre o tema desenvolvida na correspondência com Arnauld):

... do fato de que ele [Deus] tem uma inteligência perfeita da noção da substância singular considerada como possível, [decorre que] ele tem também a noção de seus [da substância criada] decretos, mas considerados igualmente como possíveis, porque, enquanto as verdades necessárias envolvem apenas o entendimento divino, as verdades contingentes envolvem os decretos da vontade. Deus vê certamente que ele pode criar as coisas de uma infinidade de maneiras, e que tal ou tal série de coisas será produzida, conforme ele escolha tais leis da série ou tal de seus decretos primitivos. Daí porque do próprio fato de que ele considera esta Mente, que envolve esta série de coisas, ele considera também o decreto que esta Mente e esta série envolvem: um e outro como possíveis, pois ele ainda não estabeleceu sua decisão; dito de outra forma, ele ainda não decidiu quais decretos ele escolherá e de quais séries, tanto os decretos gerais quanto os decretos especiais ligados às séries. Enfim, quando Deus escolhe [que existirá] uma das séries e esta Mente que nela está envolvida (revestida de seus acontecimentos), ele toma também por isso mesmo uma decisão relativa àqueles dentre seus decretos, isto é, às leis das coisas, que estão envolvidos nas noções das coisas que devem ser escolhidas. E porque Deus, ao decidir escolher esta série, faz também uma infinidade de decretos concernentes a todas as coisas que estão envolvidas nela e, portanto, concernentes a seus [de Deus] decretos possíveis, isto é, às leis que devem passar da possibilidade à atualidade, vêse assim que o decreto que Deus observa ao decidir não é o decreto pelo qual Deus decide torná-lo atual, isto é, aquele pelo qual ele escolhe [que exista] esta série de coisas, bem como esta Mente promovida nela à existência, e este decreto nela. Dito de outra forma, o decreto possível envolvido tanto na série como na noção das coisas que intervêm na série não é o decreto pelo qual ele decide tornar atual este decreto possível. Deve-se ficar tão menos surpreso com esta reflexão acerca de um decreto em um outro [quando se considera] que os decretos livres da vontade divina sejam o objeto do entendimento divino, antes que ele os conceba como realizados. De fato, Deus não faz nada sem que ele saiba que o faz ${ }^{26}$.

26 "Verdades necessárias e verdades contingentes" - In: Couturat 16-24 (Tradução de M. Fichant, In: Recherches générales sur l'analyse des notions et des vérités, 24 thèses métaphysiques et autres textes logiques et métaphysiques. Paris, PUF, 1998). Para um maior desenvolvimento desse ponto, cf. Carta de 

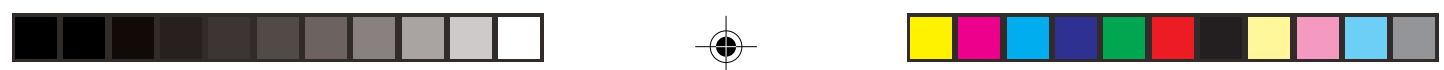

Porém, ainda que as verdades contingentes apresentem um caráter factual baseado na vontade divina considerada como possível, não se trata de um fato puramente extrínseco, pois ele é infinitamente compossível com as demais infinitas propriedades do objeto. Deus escolhe incluir o atributo "ser azul” na substância "o livro que comprei ontem” porque é essa propriedade que racionaliza a série infinita. Ou seja, a racionalização ocorre quando é incluído na série infinita o limite para o qual tendem todos os demais elementos da série. Não é contraditório negar que o livro que comprei ontem seja azul, mas é certo (desde toda a eternidade) que ele é azul, dado (a)- que isso é o mais racional, (b)- que ser racional é uma perfeição de Deus e (c)- que Deus quer (escolhe) realizar ações compatíveis com suas perfeições ${ }^{27}$. Em outras palavras, trata-se de mostrar que é verdade que uma propriedade $\mathrm{P}$ deve ser atribuída à série infinita $\alpha$ que converge infinitamente para $\mathrm{P}$ e que é possível saber isso a priori — ou seja, por princípio (i.e., para Deus) é certo que a contém P, embora que a seja P não seja uma verdade necessária (voltarei a esse aparente paradoxo de um conhecimento a priori que não gera uma verdade necessária um pouco mais adiante, quando examinar a questão acerca da bondade de Deus e se ele poderia querer não ser perfeito) ${ }^{28}$. A série infinita gera, portanto, uma forma de inclusão do conceito do predicado no conceito do sujeito que não pode ser compatível com uma relação puramente extrín-

Leibniz a Arnauld de 4 ou 14 de julho de 1686 (reproduzida em Leibniz - Discours de Métaphysique et Correspondance avec Arnauld. Introdução, texto e comentário por Georges Le Roy. Paris, Vrin, 1988, Carta X. Ver tb. Carta IX).

27 Cf. "Sobre a liberdade", p. 333: Deus "vê" a série infinita, de tal modo que uma verdade contingente "est née pour partie de son entendement, pour partie de sa volonté"; quanto às mentes criadas, "il nous reste pour notre part deux voies pour connaître les vérités contingentes. L'une passe par l'expérience, l'autre par la raison. Nous connaissons par expérience lorsque nous percevons suffisament la chose par les sens. Nous connaissons par la raison à partir du principe général selon lequel rien n'arrive sans raison, c'est-à-dire que le prédicat est toujours dans le sujet pour une certaine raison. C'est pourquoi nous pouvons tenir pour certain que Dieu fait tout de la manière la plus parfaite et qu'aucun de ses actes ne va contre la raison; que jamais rien ne survient sans que celui qui comprend ne puisse comprendre la raison, c'est-à-dire savoir pourquoi l'état de choses se comporte ainsi plutôt qu'autrement"

28 Cf. "Verdades necessárias e verdades contingentes" - In: Couturat 17: “... il n'appartient qu'à Dieu seul, qui comprend par un seul act tout l'infini, de voir complètement comment un terme est dans un autre et de comprendre a priori la raison parfaite de la contingence. Pour nous, les créatures l'expérience a posteriori y supplée". Dizer que Deus vê por intuição intelectual a série infinita não significa que a verdade das proposições que a descrevem é por isso necessária; ao contrário, a visão de Deus, justamente porque visa o infinito, é a compreensão a priori da "razão perfeita da contingência" (a conseqüência que geralmente se tira de passagens como essa é, portanto, a oposta da conclusão que deveria ser retirada). Se uma série infinita contém elementos que são infinitamente compossíveis com uma determinada propriedade $\mathrm{P}$, isso significa que, a cada nova propriedade considerada, (a)- ela se revela compativel (nãocontraditória) com $\mathrm{P}$ e (b)- ela acrescenta uma nova explicação de por que $\mathrm{P}$ é o caso (lembremo-nos da analogia com a matemática, na qual a soma $[1 / 2+1 / 4+1 / 8+\ldots]$ aproxima-se cada vez mais do número 1 , a tal ponto que podemos saber que a soma infinita tende infinitamente a 1; lembremo-nos também da analogia com uma série causal, na qual cada elemento da série pode ser usado em uma explicação de por que o objeto em questão apresenta tal ou tal propriedade). Ou ainda: a cada nova propriedade considerada, (a')- nada se revela incompatível (contraditório) com P, e (b')- nada serve de evidência para a exclusão de P. 
seca. Essa relação peculiar (que dá razões para os decretos possíveis de Deus) é uma certa aplicação do Princípio de Continuidade, que Leibniz formula assim:

Quando a diferença entre dois casos pode ser diminuída para além de toda grandeza dada in datis ou naquilo que é posto, é preciso que ela possa se encontrar também diminuída in quaesitis ou naquilo que dela resulta, ou, para falar mais familiarmente, quando os casos, ou aquilo que é dado, se aproximam continuamente e se perdem enfim um no outro, é preciso que as seqüências ou acontecimentos (ou aquilo que é demandado) o façam também ${ }^{29}$.

Em suma, deve haver simetria entre as hipóteses e as conclusões, e essa assimilação, apesar de ser o fruto de uma decisão, não é um mero procedimento pragmaticamente útil: ela tem um fundamento in re, pois, ainda que não haja identidade estrita (daí a necessidade de um ato de decisão da vontade), toda diferença entre afirmar a propriedade P como interna ou externa à série é ainda menor do que qualquer diferença assinalável. (É por isso, por ex., que se pode assimilar o repouso a um movimento infinitamente pequeno.) Traduzindo essa tese para o domínio da semântica, da epistemologia e da ontologia, pode-se dizer que a qualquer razão apresentada para distinguir $\alpha$ de $P$ pode-se apresentar outra razão para identificá-los, e assim ao infinito, de tal modo que sua identidade (ou, neste contexto, onde está envolvida a comparação de "graus de identidade", sua semelhança) com uma série ideal em tudo igual a $\alpha$, mas que contém P como um elemento "interno", será sempre maior do que qualquer diferença assinalável. No entanto, como vimos acima, essa afirmação de que a é $\mathrm{P}$ não se produz sem um ato da vontade que a estabeleça, i.e., que transforme o grau infinito de semelhança numa identidade ideal com a série que contém P. A convergência infinita, apesar de ser o fundamento in re dessa decisão, não elimina essa última como um requisito necessário da atribuição de $\mathrm{P}$ a $\alpha$. Isso mostra que há um critério de possibilidade que é diferente do simples Princípio de Contradição, a saber, um conceito de possibilidade que deriva da conjunção do Princípio de Razão Suficiente com o Princípio de Perfeição.

De fato, uma conseqüência da minha interpretação desses textos de Leibniz é que Deus, ao pensar nos mundos possíveis, ou ao menos ao pensar nos melhores mundos possíveis (i.e., este mundo atual e os mundos nas suas cercanias), não usa como único critério o Princípio de Contradição. Esses mundos possíveis também obedecem a certos critérios de racionalidade que impedem que eles contenham "disparates” (se a série $\alpha$ tende infinitamente a P,

29 GP III 52, citado em Recherches..., pp. 319-320, nota (95). 

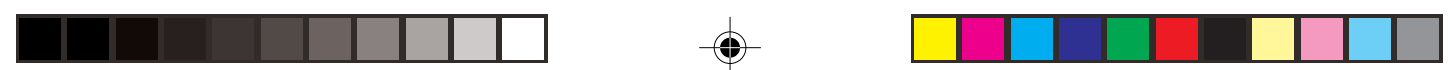

$\mathrm{P}$ faz parte do mundo no qual se encontra a série a - justamente porque $\mathrm{P}$ faz parte do sujeito designado por $\alpha)^{30}$. O conjunto dos melhores mundos possíveis é um subconjunto dos mundos logicamente possíveis; todo mundo possível é ao menos logicamente possível, mas um mundo que é apenas logicamente possível (se é que isso é pensável) pode ser uma coleção de propriedades coexistindo acidentalmente. Deus pode pensar nessas coleções, mas não pode - o que é o mesmo que dizer, como veremos adiante, que não quer criá-las como um mundo atual, submetidas ao espaço e ao tempo. Ou seja, ser racional envolve mais do que pensar em objetos não contraditórios: há critérios de congruência e de coerência relativos aos fatos que devem ser observados. É por isso, creio, que Leibniz afirma, na carta a Arnauld de 14 de julho de 1686, que, no caso dos objetos gerais e abstratos, como o Círculo geométrico, a compreensão de sua essência depende apenas do intelecto de Deus, sem a consideração de Seus decretos, pois trata-se aí de propriedades necessárias; já no caso das predicações contingentes, é preciso que a vontade de Deus intervenha ${ }^{31}$.

Se a conexão entre $\alpha$ e P não é necessária, então é (logicamente) possível pensar que $\alpha$ é não-P (ou, se quisermos evitar propriedades negativas, que é falso que $\alpha$ seja P). Mas não é (realmente) possível que seja falso que $\alpha$ seja P: dada aquela série, a contém P. No entanto, dizer que não é realmente possível não significa que Deus não possa fazê-lo, mas antes que ele não quer

30 Essa introdução de um tipo de possibilidade mais forte do que a mera possibilidade lógica é particularmente clara no "Prefácio" aos Novos ensaios: "Ainsi, dans l'ordre de la nature (les miracles mis à part), il n'est pas arbitraire à Dieu de donner indifférement aux substances telles ou telles qualités, et il ne leur en donnera jamais que celles qui leur seront naturelles, c'est-à-dire qui pourront être dérivés de leur nature comme des modifications explicables. Ainsi on peut juger que la matière n'aura pas naturellement l'attraction mentionée ci-dessus, et n'ira pas d'elle-même en ligne courbe, parce qu'il n'est pas possible de concevoir comment cela s'y fait, c'est-à-dire de l'expliquer mécaniquement, au lieu que ce qui est naturel doit pouvoir devenir concevable distinctement si l'on était admis dans les secrets des choses. Cette distinction entre ce qui est naturel et explicable et ce qui est inexplicable et miraculeux lève toutes les difficultés: en la rejetant, on soutiendrait quelque chose de pis que les qualités occultes et on renoncerait en cela à la philosophie et à la raison, en ouvrant des asiles à l'ignorance et à la paresse, par un système sourd qui admet non seulement qu'il y a des qualités que nous n'entendons pas, dont il n'y en a que trop, mais aussi qu'il y en a que le plus grand esprit, si Dieu lui donnait toute l'ouverture possible, ne pourrait pas comprendre, c'està-dire qui seraient ou miraculeuses ou sans rime et sans raison; et cela même serait sans rime et sans raison que Dieu fit des miracles ordinairement, de sorte que cette hypothèse fainéante détruirait également notre philosophie, qui cherche des raisons, et la divine sagesse, qui les fournit". Sobre esse mesmo tópico, cf. Laurence Bonjour, "The Coherence Theory of Empirical Knowledge" (in Philosophical Studies 30 (1976), pp. 281-312): “... coherence is not to be equated with consistency. A coherent system must be consistent, but a consistent system need not be very coherent. Coherence has to do with systematic connections between the components of a system, not just with their failure to conflict" (p. 288). Cf. nota (35) abaixo.

31 Seria preciso determinar precisamente quais são as condições em que Deus pode - e aquelas nas quais nós mesmos podemos - pensar em um "Judas fiel ao Cristo"; uma característica que aproxima essas verdades contingentes das verdades sobre essências necessárias é que, também no caso dos juízos contrafactuais relacionados a objetos singulares, a referência do termo sujeito é um objeto geral e abstrato, a saber, o "Judas genérico". 
fazê-lo; Deus não o quer porque ele é um ser racional, e porque não é racional fazê-lo. O que é realmente impossível é possível para Deus, já que ele é a origem da realidade. Trata-se, assim, de introduzir um novo tipo de necessidade (física ou real) na explicação das coisas reais. Mas essa necessidade física depende da vontade de Deus de construir um universo seguindo leis gerais e racionais. Todas as leis são promulgadas livremente por Deus e, nesse sentido, poderiam (lógica e metafisicamente) não ocorrer. Dada, porém, a vontade de Deus de ser racional, é (realmente) necessário que não haja disparates no mundo atual e ao menos nos melhores mundos possíveis, ainda que essa necessidade decorra da vontade contingente de Deus. Ela é uma necessidade hipotética (o que, aliás, é o sentido mais relevante dessa expressão, que introduz uma condição que se refere menos à ordem infinita das coisas do que à vontade de divina).

Deus poderia querer não ser perfeito? Ele poderia querer criar disparates? Essa questão tem um sentido análogo à questão sobre se Deus poderia não ser bom ${ }^{32}$. Certamente, a bondade é uma perfeição, e Deus é um ente sumamente perfeito (ter essa essência não é objeto de uma escolha), mas "ser bom" não é uma propriedade que se tem de modo meramente passivo, tal como "ser azul” ou "ser o segundo filho de alguém"; "ser bom" depende de um ato da vontade a partir do qual se decide que se quer ser bom. Ou seja, só é bom quem pode não ser bom. Deus poderia querer criar disparates (e, em um certo sentido, ele pode fazê-lo, como quando pensa, por abstração, no Judas realmente existente como fiel ao Cristo, pois tudo o que é possível pode existir), mas, porque sabemos a priori que ele é perfeito e, portanto, que, sendo onisciente, ele quer ser bom (e que, sendo onipotente, ele pode ser bom), também sabemos a priori que, se Judas pecou, isso já estava contido em seu conceito completo, de tal modo a maximizar a coerência e a bondade do mundo no qual Judas existe ${ }^{33}$, mundo esse que é o verdadeiro objeto da escolha de Deus (Deus, sendo onisciente, sabe a priori, desde toda a eternidade, que Judas pecará; nós, mentes finitas, só podemos constatá-lo a posteriori e saber que, metafisicamente falando, tal ato pertence ao conceito completo em questão — onde o advérbio "metafisicamente” não significa, é claro, que se trata de conexões necessárias, mas apenas de raciocínios necessários sobre o contingente).

32 Ou seja, essa questão colocaria um problema tanto para minha interpretação quanto para a tese leibniziana segundo a qual Deus poderia não ter escolhido o melhor dos mundos possíveis para ser o mundo existente (isto é, isso seria um problema tanto para a tese acerca da contingência da predicação quanto para a tese acerca da contingência da existência).

33 Coerência e bondade (e beleza) são nomes diversos da harmonia que explica a passagem para a existência do melhor dos mundos possíveis, i.e., daquele que contém o maior grau de essência. 

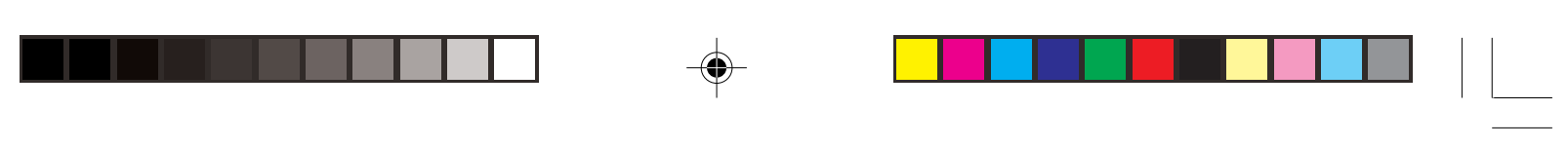

Porém, mesmo que afirmássemos que é necessário que Deus escolha o melhor dos mundos possíveis porque Ele é bom, disso não se seguiria que o mundo atual seja necessário; como explica Leibniz:

\begin{abstract}
Devemos examinar se, se supusermos que esta proposição é necessária: a proposição que tem a maior razão para existir existe, segue-se que a proposição que tem a maior razão para existir é necessária. Mas a inferência é corretamente rejeitada. Pois, se a definição de uma proposição necessária é que sua verdade pode ser demonstrada com rigor geométrico, então pode de fato ocorrer que esta proposição possa ser demonstrada: cada verdade, e somente uma verdade, tem a maior razão, ou esta: Deus sempre age o mais sabiamente possível. Mas não será, a partir daí, possível demonstrar esta proposição: a proposição contingente A tem a maior razão, ou a proposição contingente A é conforme à sabedoria divina. Logo, tampouco se segue que a proposição contingente A é necessária. E, portanto, mesmo se fosse concedido que é necessário que Deus escolha o melhor, ou que o melhor é necessário, ainda assim não se segue que o que é escolhido seja necessário, uma vez que nenhuma demonstração de que ele é o melhor é dada ${ }^{34}$.
\end{abstract}

Não creio que, na última frase da citação, Leibniz esteja realmente concedendo que seja necessário que Deus escolha o melhor, mas apenas examinando o que se seguiria dessa hipótese, para refutar mais cabalmente a atribuição de necessidade às coisas criadas. De acordo com essa refutação, não seria contraditório negar que Deus escolhe a proposição contingente A; logo, há um decreto possível de Deus que tem a negação de A como objeto. Essa contingência, porém, é compatível com o fato de que, no interior do mundo criado, as leis da natureza são necessárias.

A necessidade física manifesta-se, portanto, como leis naturais (físicas ou psicológicas), as quais, em um vocabulário fenomênico, são expressas em termos causais, mas que, em vocabulário metafísico, são expressas em termos de compatibilidade, congruência e harmonia, e estão submetidas ao decreto geral que regula cada mundo possível tomado em sua totalidade e avaliado em vistas de sua finalidade última ou grau de perfeição. Afirmar que as leis da natureza são fisicamente necessárias não significa afirmar que as leis que constituem este mundo atual são as mesmas em todos os mundos possíveis (se fosse assim, elas não seriam contingentes nem explicariam a contingência). No entanto, as leis da natureza válidas em outros mundos, mesmo sendo diferentes das leis da natureza vigentes neste mundo, impõem, em todos os mundos possíveis, ou ao menos nos melhores dentre eles, restrições mais fortes do que o simples Princípio de Contradição ${ }^{35}$.

34 Ver Gr 305f/AG 30 (citado por Adams, op. cit., pp. 23-24).

35 Sobre esse tópico, cf. o excelente artigo de H. Ishiguro, "Leibniz and the Ideas of Sensible Qualities", em G. W. Leibniz: Critical Assessments, Vol. IV., ed. by R. S. Woolhouse, London, Routledge, 1994, pp. 103116 , no qual ela chega, por vias diversas (no contexto de uma discussão sobre os critérios de identidade 
Se quiséssemos modalizar as proposições sobre o ser (i.e., se quiséssemos exprimir metafisicamente o significado de "necessidade" e de "possibilidade" aplicados ao que realmente existe no mundo, as substâncias singulares), poderíamos dizer que é logicamente necessário que haja pelo menos uma e não mais do que uma instância de uma espécie ínfima; que é logicamente necessário que a existência instancie plenamente a essência; que é logicamente necessário que todos os elementos de uma espécie ínfima (como os de toda espécie), pertençam àquela espécie (de tal modo que, se uma propriedade mudar, não se trata mais da mesma espécie), mas que não é logicamente necessário que, dada uma propriedade P, ela se deduza das demais propriedades da série infinita à qual pertence — ou seja, as propriedades das séries infinitas não estão conectadas entre si por necessidade lógica, apesar de haver relações lógicas entre cada uma delas (da mesma forma, as séries de números infinitos progridem não-aleatoriamente, a partir de uma certa $r a-$ $(i o)^{36}$. Ainda assim, a introdução de um sentido de "possibilidade" mais forte

de propriedades) a uma conclusão similar à minha. Cf. especialmente pp. 112-113: "It is possible to give a description of a world in which some of our natural laws do not hold - so long as enough natural laws are common to our world and this possible one, such that we can use our concepts to describe this one"; essa não é uma limitação apenas para as mentes criadas, mas diz respeito às próprias condições de individuação das coisas em si mesmas: "...although one can conceptually distinguish logical necessity ('true in all possible worlds') and physical necessity (necessary, given the initial conditions of a world), their mutual relation is a very complex one. Physical necessity and logical necessity are intricately intertwined in our thoughts about possible worlds. As Leibniz says, we do not individuate things as bundles of accidentally coexisting properties. We individuate things in a world of natural law, and so the criterion of individuation is bound up with our nomological precepts. The criterion of identity of the thing to which we ascribe the properties depends a great deal on notions of its constitution - e.g. that they occupy one place and only one place at a particular time, or that they move following certain laws, that they expand or diminish in size according to certain laws, etc. For Leibniz an individual substance is above all a unit of action. The way we individuate cells, or fail to individuate elementary particles, could hardly be independent of our nomological concepts. It folows that all talk of coextensiveness of properties, which presuppose individuation of entities which have the properties, is dependent on our nomological concepts".

36 Nesse sentido, creio ser equivocada a objeção de Blumenfeld ("Leibniz on Contingency and Infinite Analysis" - in: Philosophy and Phenomenological Research. Vol. XIV, n. 4, junho de 1985), segundo a qual Leibniz parece enredado em um paradoxo, na medida em que ele tem de admitir simultaneamente que "every proposition which asserts that one of these elements is contained in the concept of Peter is necessarily true, but the proposition that expresses the entire definition (or the complete concept) is contingent". Blumenfeld chega a essa conclusão a partir da consideração de que, se o conceito completo de Pedro é composto, dentre outras infinitas propriedades, por $p, q$ e $r$, então a proposição que afirma que o conceito de Pedro contém $p$ é uma verdade necessária, pois pode ser demonstrada em um número finito de passos; já no que se refere à prova de que o conceito de Pedro contém $p, q, r$, et cetera ad infinitum, não é possível haver uma prova finita, pois se trata de uma conjunção infinita - logo, ela é uma verdade contingente. Ora, segundo minha argumentação, é justamente o oposto que é o caso: para cada propriedade tomada em particular, é contingente que ela pertença à série infinita da qual faz parte, ainda que, considerando a série inteira, seja necessário que todos os seus elementos façam parte dela - pois, do contrário, não seria mais a mesma série. Creio que essa diferença nos resultados entre o meu texto e o de Blumenfeld deve-se ao fato de eu ter partido de um ponto de vista genético no que diz respeito à formação do conceito completo das substâncias singulares - ou seja, de ter adotado a explicação da contingência a partir da relação de criação do mundo por Deus. É claro que, se supusermos que $p, q$ e $r$ fazem parte da série, então necessariamente $p$ faz parte da série. Mas a pergunta correta é: dada a série completa, com exceção de $p$, como é possível saber a priori que $p$ pertence ou não àquela série? Deus pode saber disso a priori, não porque "veja" uma conexão necessária, mas porque seu intelecto é infinito como a série que ele compreende intuitivamente. 
do que o de mera possibilidade lógica (o que chamei acima de "possibilidade real”, ligada às leis da natureza) não faz com que o sentido de possibilidade envolvida na caracterização dos mundos possíveis implique que essa possibilidade não é necessária. Todas as leis da natureza que forem logicamente possíveis (i.e., que obedecerem o Princípio de Não-Contradição) serão pensáveis pelo intelecto de Deus como objetos de seus decretos possíveis. Logo, tudo o que é possível é necessariamente possível, ou seja, implicaria contradição negar sua possibilidade ${ }^{37}$.

Vemos também que a resposta de Leibniz para o problema da conciliação de determinismo e contingência através da análise infinita não é uma resposta epistemológica para um problema ontológico ${ }^{38}$. Há certamente um apelo às noções de prova, evidência e conhecimento, mas apenas na medida em que elas esclarecem certas relações lógicas, isto é, do ser das coisas que podem ser conhecidas. Ou seja, trata-se da análise lógica das coisas reais consideradas como objetos de um conhecimento possível.

A análise infinita é, assim, uma maneira engenhosa de conciliar a contingência com a inteligibilidade total do real. Para a mente infinita de Deus, não há nada de ininteligível em uma série infinita; a contingência não deriva da matéria ou de uma vontade cega, mas da vontade guiada para o Verdadeiro e para o Bem. Ainda assim, a infinitude da série produz uma diferença qualitativa na predicação a ela atribuída: a contingência é qualitativamente distinta da necessidade, mas cada um de seus infinitos elementos é inteligível, bem como sua conexão infinita. Logo, há contingência real no mundo, mas tudo é predeterminado.

Porém, antes de dar por encerrada a discussão, é desejável resumir da forma a mais intuitiva possível o resultado alcançado. O objetivo de meu texto era o de mostrar como é possível compatibilizar determinismo e contingência. A compatibilização foi demonstrada através do conceito de leis da natureza, entendidas como expressão da vontade de Deus. Mas esse resultado, expresso assim intuitivamente, pode parecer ou muito decepcionante (na medida em que só enunciaria uma trivialidade, a saber, que as coisas que existem seguem leis naturais, mas são contingentes porque poderia existir um mundo no qual essas coisas ou essas leis não existissem) ou simplesmente

37 Tomei consciência desse último aspecto ao ler o texto de Edgar Marques, intitulado "Observações críticas acerca da noção leibniziana de decretos divinos possíveis", incluído no presente número desta revista. O texto de E. Marques, porém, propõe, contrariamente ao que afirmo aqui, que há nesse tópico uma dificuldade incontornável para a teoria de Leibniz.

38 O próprio Blumenfeld reconhece que Leibniz não pretendia ter apresentado uma solução "espinosista", segundo a qual a contingência seria explicada pela limitação de nosso conhecimento, e não pela estrutura da realidade. 
errado (na medida em que reintroduz uma noção forte de determinismo natural incompatível, poder-se-ia suspeitar, com a contingência real, e não meramente lógica, dos eventos do mundo).

Quanto à decepção, creio que ela poderia ser amenizada se considerarmos que o que foi demonstrado não foi somente que o mundo atual, com suas leis, objetos e propriedades, poderia não existir, existindo no seu lugar um outro mundo (muito ou pouco) diferente, mas antes que as conexões existentes entre as propriedades e os objetos deste mundo atual são contingentes na medida em que as leis naturais são compreendidas como expressão da vontade de Deus, ou seja, como algo que poderia não ser tal como de fato é. A teoria leibniziana fornece um critério para distinguir conexões necessárias de conexões contingentes (ou seja, essência e acidentes ${ }^{39}$ ) no interior deste mundo atual.

Quanto ao erro, deve-se notar que a idéia de Leibniz acerca da lei natural é fraca o bastante para permitir a contingência, mas forte o bastante para permitir o determinismo: dado este mundo atual, as coisas não podem ser diferentes do que são ${ }^{40}$, mas elas são o que são em conseqüência da vontade de Deus, não apenas no sentido de que Sua vontade se expressa nas leis naturais, mas sobretudo quando se considera que essas leis se aplicam ao conjunto infinito de propriedades simples. Ou melhor, as leis não são nada além do que as regularidades que asseguram que as infinitas coisas e suas infinitas propriedades estejam conectadas tal como Deus determina que estejam, sem que nenhuma necessidade metafísica intervenha; se fosse preciso "ajustar" essas leis para unir uma certa propriedade a uma coisa singular (ou a um tipo geral de coisa), seriam introduzidas novas leis subordinadas da natureza ${ }^{41}$.

39 Como vimos, ao contrário do que supõe Mondadori, portanto, a distinção entre essência e acidentes não pode ser explicada apenas pela distinção temporal entre propriedades permanentes e propriedades ocasionais das coisas. Cf. sobre esse ponto Vailati, op. cit., p. 333.

40 Aqui não interviria nada além do que o Princípio de Contradição aplicado ao mundo atual considerado como uma totalidade dada (ou seja, como um objeto lógico instanciado, mas considerado do ponto de vista da eternidade, "fora" do tempo): se $x$ é dado, é contraditório afirmar que não é dado (embora não seja contraditório afirmar que poderia não ser dado). Ou, de modo mais intuitivo (usando a noção de tempo): se um fato contingente ocorreu, é contraditório negar que tenha ocorrido, mas isso não significa afirmar que era necessário que ele ocorresse - significa apenas que o passado é necessário.

41 Salvaguardando-se sempre o Princípio de Perfeição, segundo o qual o melhor dos mundos possíveis é aquele que I- é composto pela maior variedade (quantitativa e qualitativa) de fenômenos regulada pelo menor número possível de leis, e II- contém a maior perfeição moral compatível com a criação (i.e., a conjunção ótima de moralidade e felicidade relativa à consciência limitada dos homens). $O$ apelo à noção de "leis da natureza" poderia ser questionado aqui de outra forma, a saber: o tipo de determinismo que Leibniz pretendia compatibilizar com a contingência não é o determinismo natural, expresso por leis causais, pois, a rigor, não existe causalidade entre substâncias no sentido metafísico estrito; o determinismo visado é o temporal, segundo o qual uma certa ordenação do passado determina o presente e o futuro. A resposta a essa objeção já está dada pelo argumento anterior: as leis maximamente universais, que se expressam no mundo fenomenal como relações causais, são, do ponto de vista metafísico, funções que exprimem intensionalmente, no intelecto divino, a fórmula completa que descreve a essência de um certo mundo possível (desde que a essas leis sejam acrescidos os milagres). Neste ponto, é importante obser- 
De um ponto de vista metafísico, devemos entender que Deus "distribui” as infinitas propriedades dentre os infinitos objetos do mundo, e que as leis da natureza não são nada além do que o meio através do qual essa distribuição de propriedades é organizada segundo regularidades (até certo ponto) observáveis. Os decretos possíveis de Deus compõem assim mundos possíveis, do mesmo modo que nossa imaginação voluntariamente "molda" seres fictícios; do ponto de vista do intelecto divino, esses decretos possíveis causam a produção efetiva de objetos possíveis, isto é, de coisas que podem ou não vir a existir $^{42}$.

Se o domínio de objetos sobre o qual Deus “distribuísse” as propriedades fosse finito (e se essas últimas também fossem finitas), a vontade divina produziria apenas uma contingência de existência, e não de predicação — ou seja, a distribuição das propriedades seria expressa por uma análise combinatória e tudo o que dependeria da vontade de Deus seria a atribuição de existência a um dos conjuntos assim gerados. Como vimos, um objeto com um número finito de propriedades contém ou não contém de modo necessário

var que os milagres devem ser admitidos no sistema simplesmente porque é possível provar que eles não são contraditórios. Mas é preciso observar também que a referência aos milagres ganha destaque porque ela desempenha uma função argumentativa essencial, a saber: eles mostram que as leis da natureza não devem ser tomadas como uma totalidade absoluta e autocontida, mas devem ser compreendidas como repousando sobre um fundamento metafísico, ele sim absoluto, de modo que elas sejam compreendidas como contingentes (o próprio fundamento, Deus, apresenta uma vontade contingentemente determinada para o Bem). Devemos nos lembrar da insistência de Leibniz em afirmar que as "leis maximamente universais da natureza" (eqüivalentes ao que poderíamos chamar da "fórmula" complexa que expressa a essência do universo) englobam tanto as leis subalternas da natureza quanto os milagres, tendo em vista a Perfeição moral da criação.

42 Sobre a comparação entre as ficções de nossa imaginação e os decretos de Deus, cf. Novos Ensaios, Livro II, Cap. 30, "Das idéias reais e quiméricas": Teófilo concorda com a tese exposta por Filaleto (embora amplie seu escopo para o caso das próprias idéias simples) segundo a qual a combinação que a mente faz "pour former des idées composées, où plusieurs simples sont comprises sous un même nom, ont quelque chose de volontaire" (§ 3); Teófilo acrescenta logo adiante, em outra generalização da tese inicial: "Les relations ont une réalité dépendante de l'esprit comme les vérités; mais non pas de l'esprit des hommes, puisqu'il y a une suprême intelligence qui les détermine toutes de tout temps" (§ 4). É verdade que nesse texto ele caracteriza essa dependência unicamente pelo intelecto divino, sem a consideração de sua vontade ("il suffit pour la réalité de leurs idées que ces modes soient possibles ou, ce qui est la même chose, intelligibles distinctement. Et pour cet effet, il faut que les ingrédients soient compossibles, c'est à dire qu'ils puissent consister ensemble"). Como vimos acima, porém, isso não vai contra minha interpretação, pois o conjunto dos decretos possíveis de Deus é dado nos limites estabelecidos apenas pelo Princípio de Não-Contradição - ou seja, tudo o que é possível é necessariamente possível, de tal modo que o intelecto de Deus contém todas as leis naturais que são logicamente possíveis. Deve-se notar que, no final desse capítulo dos Novos Ensaios, Leibniz assinala que "les idées possibles deviennent seulement chimériques lorsqu'on y attache sans fondment l'idée de l'existence effective" (§ 5), ou seja, que não há diferença de natureza entre o quimérico e o possível. Sobre uma outra comparação entre o modo como produzimos voluntariamente nossas idéias e o intelecto de Deus, cf. Discurso de metafísica, Art. 14: "... les substances crées dépendent de Dieu qui les conserve et même qui les produit continuellement par une manière d'émanation, comme nous produisons nos pensées. Car Dieu tournant pour ainsi dire de tous côtés et de toutes les façons le système général des phénomènes qu'il trouve bon de produire pour manifester sa gloire...". É verdade que a comparação diz respeito ao mundo que efetivamente existe, cuja duração na existência depende de uma criação contínua. Mas a frase introduz uma certa ação da vontade na geração dos próprios mundos possíveis. 
cada uma das propriedades que ele contém ou não contém. Essa necessidade não decorre do fato de que, variando as propriedades, estaríamos nos referindo a um outro objeto, pois a identidade dos indiscerníveis também vale para os objetos dotados de infinitas propriedades; antes, ela decorre do fato de que, para cada propriedade, é possível demonstrar se ela pertence ou não ao objeto em questão $0^{43}$.

Assim, o ato mais primitivo, poderíamos dizer, é a representação, no espaço lógico, dos objetos singulares dotados de suas respectivas propriedades, observando-se os critérios da compossibilidade e da coerência; secundariamente, seguem-se as leis, que são representadas como os elos e a forma de instanciação desses objetos. Aparentemente, a mera representação de objetos é dada levando-se em conta apenas o entendimento de Deus, mas essa impressão, como vimos, é falsa, pois deve haver referência à sua vontade, considerada como possível. É preciso considerar as leis da natureza não como uma totalidade absoluta e autocontida ${ }^{44}$, que impõe uma necessidade fatalista às coisas, mas antes como um produto de algo contingente, a vontade divina, a qual, por sua vez, é a faculdade de um ser necessário. É apenas quando consideramos as leis da natureza como uma totalidade absoluta que elas se mostram incompatíveis com a contingência, pois, nesse caso, a única forma de contingência imaginável seria a possibilidade de outros mundos (entendidos como totalidades autocontidas), sem que a contingência no interior de cada um deles fosse preservada. Todo o esforço de Leibniz consiste justamente em nos colocar em um ponto de vista "externo" ao mundo criado, onde a contingência das leis da natureza se torna compreensível. (Seria possível imaginar que Deus "distribuísse” as propriedades no mundo seguindo para cada uma delas uma lei particular; entretanto, sendo Deus um artífice perfeito, ele aglutina esses desígnios particulares em leis simples e "maximamente

43 Mesmo que não exista uma conexão racional entre as propriedades dos objetos finitos, tendo esses sido gerados a partir da distribuição aleatória de propriedades compossíveis, é verdade que cada propriedade pertence necessariamente ao conjunto finito ao qual pertence, pelo simples fato de que esse objeto é dado como um conjunto finito, permitindo, dessa forma, um método de verificação exaustivo - por ex., percorrer extensionalmente seu domínio de propriedades - que eqüivaleria, no caso dos finitos, a uma demonstração necessária. O que seria demonstrado dessa forma não seria apenas que uma certa propriedade pertence à série (pois, nesse caso, ao percorrermos uma série infinita, poderíamos nos deparar, em poucos passos, como a propriedade buscada), mas que, para cada propriedade, é possível demonstrar se ela pertence ou não à série. $O$ fato de que o número de propriedades pode ser finito e enorme (tão grande que não poderia ser apreendido pelo intelecto humano), como vimos, não altera em nada a distinção proposta, pois essa distinção está baseada na possibilidade de ser gerada uma contradição da negação de que uma certa propriedade pertença a um dado objeto (além da contradição que é gerada também no caso dos objetos dotados de infinitas propriedades, pela mera aplicação do Princípio da Identidade dos Indiscerníveis). Isso mostra, mais uma vez, que a distinção entre necessidade e contingência não é uma distinção epistêmica.

44 Cf. supra nota (41). 
universais”45, que, porém, são tão contingentes quanto se existisse uma lei particular para cada coisa existente ${ }^{46}$ ).

Portanto, a idéia de lei natural, tal como interpretada por Leibniz, não introduz um determinismo forte o bastante para eliminar a idéia de contingência da predicação, justamente porque a série em questão é infinita (se fosse finita, a "distribuição" seria determinada de modo estrito, i.e., necessária, e independeria da vontade de Deus), e, dessa forma, a contingência não se reduz à possibilidade deste mundo atual não existir. Mas a sucessão infinita da série comporta predição e predeterminação, isto é, necessidade hipotética: dada a série de coisas no mundo, e exceção feita aos milagres, as coisas podem ser compreendidas como estando "submetidas" às leis da natureza. Logo, o compatibilismo proposto não é nem tão trivial ${ }^{47}$ nem errado como se poderia pensar inicialmente.

Vimos, pois, em que sentido a compreensão da natureza de Deus é, segundo Leibniz, o fundamento da metafísica, o que nos permite distinguir verdades necessárias de verdades contingentes. Entretanto, a compreensão metafísica da contingência não deve, evidentemente, ser confundida com a compreensão completa das espécies ínfimas, o que ultrapassa em muito a força de nosso intelecto criado, manifestando-se plenamente apenas no intelecto infinito de Deus.

45 Cf. supra nota (27).

46 Os milagres mostram justamente a contingência das leis universais da natureza (cf. supra, nota (41)). A rigor, um milagre é uma lei subordinada da natureza aplicada uma única vez (embora a noção de lei nesse caso seja questionável, pois ela perdeu seu caráter contrafactual; talvez fosse melhor caracterizá-lo apenas através da noção de decreto divino).

47 Deve-se lembrar que o argumento de van Inwagen (in An Essay on Free Will. Oxford: Clarendon Press, 1983) a favor da incompatibilidade entre determinismo e liberdade apresenta como suas premissas essenciais (de alguma forma auto-evidente) a impossibilidade de os agentes mudarem o passado e as leis naturais; Leibniz certamente concordaria com essas premissas (quem não concordaria? - apesar disso, ver D. Lewis, "Are We Free to Break the Laws?", in: Philosophical Papers, Vol. II. Oxford: Oxford University Press, 1986, pp. 291-298), mas enquanto a impossibilidade de mudar o passado é vista por ele como uma verdade necessária, a impossibilidade de mudar as leis não é absoluta, pois Deus, o criador das leis, poderia mudá-las. Essa diferença explica o incompatibilismo de van Inwagen e o compatibilismo de Leibniz. 